\title{
Polyacrylamide Grafted Xanthan: Microwave-Assisted Synthesis and Rheological Behavior for Polymer Flooding
}

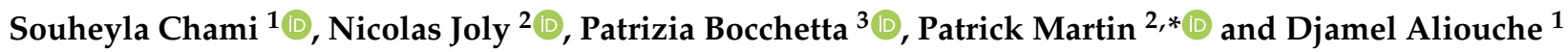 \\ 1 Laboratory of Polymers Treatment \& Forming, Faculty of Technology, M'Hamed Bougara University, \\ Boumerdes 35000, Algeria; chamis2007@yahoo.fr (S.C.); aliouche.djamel@univ-boumerdes.dz (D.A.) \\ 2 Univ Artois, UniLaSalle, Unité Transformations \& Agroressources, ULR7519, F-62408 Béthune, France; \\ nicolas.joly@univ-artois.fr \\ 3 Department of Innovation Engineering, University of Salento, Via per Monteroni, 73100 Lecce, Italy; \\ patrizia.bocchetta@unisalento.it \\ * Correspondence: patrick.martin@univ-artois.fr
}

Citation: Chami, S.; Joly, N.;

Bocchetta, P.; Martin, P.; Aliouche, D. Polyacrylamide Grafted Xanthan:

Microwave-Assisted Synthesis and Rheological Behavior for Polymer Flooding. Polymers 2021, 13, 1484 https://doi.org/10.3390/

polym13091484

Academic Editor: Giulio Malucelli

Received: 28 March 2021

Accepted: 1 May 2021

Published: 5 May 2021

Publisher's Note: MDPI stays neutra with regard to jurisdictional claims in published maps and institutional affiliations.

Copyright: (c) 2021 by the authors. Licensee MDPI, Basel, Switzerland. This article is an open access article distributed under the terms and conditions of the Creative Commons Attribution (CC BY) license (https:/ / creativecommons.org/licenses/by/ $4.0 /)$

\begin{abstract}
Application of polymer-flooding systems in secondary and tertiary oil recovery represents a real challenge for oil industry. In this work, our main objective is to explore possibilities of making use of xanthan- $g$-polyacrylamide for polymer flooding in a particular Devonian oilfield of medium salinity. The graft polymer was synthesized by using microwave-assisted graft copolymerization reaction of acrylamide on xanthan. The synthesized copolymer with optimized grafting parameters has been characterized by Infrared Spectroscopy and Thermal Analysis (DSC). Rheological analysis by steady shear and oscillatory flow experiments have been subsequently performed for xanthan and grafted xanthan under reservoir conditions. In steady shear, as expected the grafted polymer solutions flow as shear-thinning materials and apparent viscosity showed good fits with Cross's model. The viscosity losses due to salinity or temperature are more controlled for the grafted xanthan compared to pristine xanthan. When the grafted polymer concentration is increased to $2000 \mathrm{ppm}$ the losses were halved. In oscillatory shear, the copolymer solutions followed a global behavior of semi-dilute entangled systems; furthermore, all dynamic properties were influenced by the brine salinity. Compared to xanthan, the elastic properties of xanthan-g-polyacrylamide solutions have been significantly improved in saline media and the losses in elasticity of grafted polymer solutions are lower.
\end{abstract}

Keywords: xanthan; polyacrylamide; rheology; viscosity loss; viscoelasticity; enhanced oil recovery

\section{Introduction}

In oilfield operations, some techniques are used to improve recovery of additional quantities of oil and gas from the depositional field. Suitability of a process for a particular oilfield is governed by the fluid properties and field environment geology [1]. Application of polymer flooding in Enhanced Oil Recovery (EOR) systems has become an efficient and cost-effective procedure [2]. According to wellbore conditions, the mobility of water and oil as well as the relative permeability in the core reservoir are complex parameters for recovering residual oil [3,4]. Polymer solutions are added with injected brine to increase its viscosity and, therefore, control the oil mobility and lower the core permeability, even at very low concentrations [5]. In order to upgrade sweep productivity in oil recovery techniques, the role of polymer solution will be to adjust viscosity of the aqueous phase and to behave as shear-thinning material. Shear-thinning solutions can delay flow disruption at low shear rates, but they do not resist enough to flow at high shear rates. For drilling fluids, the flow performance of polymer solution is fundamental, as during flooding in porous reservoirs, polymer rheology affects both injectivity and sweep efficiency. The polymer selected for EOR should have relevant properties for flooding: water-soluble, shear thickener for water; shear thinner for crude oil mixture, low coast and non-toxic [6,7]. 
Partially hydrolyzed polyacrylamide (HPAM) and polysaccharides (xanthan and cellulose products) were widely applied in polymer flooding procedures and extensively reviewed for their application in EOR management [8-11]. Compared to polysaccharides, with its low cost, HPAM polymer can yield solutions with desired viscosity levels even at very low concentrations [12]. However, due to the screening effect of charges carried by the acrylate groups on the polymer chains, flow behavior of polyacrylamide is more affected by the presence of salts. Therefore, in more salt aqueous phase the shear resistance of polyacrylamide polymers is poor and restricts its exploitation in high salinity reservoirs [13]. Xanthan, a second water-soluble polysaccharide applied for flooding, is less affected by the presence of salts and exhibits better rheological behavior than that of HPAM [14,15]. However, the aqueous xanthan solution is deficient in elasticity; additionally, use of xanthan is restricted in high temperature reservoirs due to its weak thermal stability [16]. To improve rheology of these polymers, several alternatives have been proposed, such as chemical modification of HPAM [17-19] or combination of xanthan with other polysaccharides [20-23]. In this context, it seems interesting to combine functional characteristics of both polymers by grafting polyacrylamide onto xanthan. In a previous work, polymer flooding using xanthan biopolymer was carried out to explore its potential for improving oil recovery in a particular Algerian oil field [24]. In the present study, we focus on the polymer flooding characteristics of xanthan-graft-polyacrylamide under the reservoir conditions. Behavior of both polymers was compared in terms of viscosity and viscoelastic properties. Xanthan-g-polyacrylamide was synthesized by a fast graft copolymerization reaction under microwave irradiation. To yield copolymer with optimal characteristics, we have adjusted some parameters of the grafting reaction: presence or absence of chemical initiator, irradiation power, reaction time, xanthan polymer, and acrylamide monomer amounts. The grafted xanthan so prepared was characterized by FTIR spectroscopy. Subsequently, xanthan and grafted xanthan were evaluated for polymer flooding through their behavior in deionized water (DW) and reservoir formation water (RW) of Devonian nature, a third brine of Liassic nature was used as injection water (IW). The rheological experiments for steady shear and dynamic oscillatory flow were completed for different polymer concentrations and temperatures and polymer solutions were prepared with the brines cited above, as solvents.

\section{Materials and Methods}

\subsection{Materials}

Xanthan polymer $\left(\mathrm{Mw} \sim 5 \times 10^{6} \mathrm{Da}\right)$ was provided by AVA Drilling Fluids and Services Co., (Roma, Italy). For each experiment, polymer solution was prepared at constant temperature by slow addition of known amounts of gum in a reactor containing DW, IW or RW. Acrylamide monomer (AAm), from Sigma-Aldrich Chemie Gmbh (Munich, Germany), was purified by double recrystallization from methanol, vacuum dried at $40^{\circ} \mathrm{C}$, and then stored in a desiccator over silica gel. Initiator, Ammonium persulfate (APS), acetone, and methanol were all supplied by Panreac Monplet and Esteban, S.A. (Barcelona, Spain) and used without additional purification.

Deionized water was employed in the grafting reaction and preparation of polymerDW solutions. In most oilfields, injection water and reservoir formation brine (both contain salts) are essential water sources; their impact on rheology of polymer solutions is very significant for the flooding. The brine composition has a considerable influence on the aqueous phase viscosity. In accordance with the field geology, two brines have been used for polymer mixing: Liassic brine as injection water, Devonian one as reservoir water. Table 1 shows the chemical composition of these brines. The internal pressure in the well is of 131.1 bars; the well internal temperature is about $68^{\circ} \mathrm{C}$. 
Table 1. Chemical composition of brines used for rheology tests.

\begin{tabular}{ccc}
\hline \multirow{2}{*}{ Parameters } & \multicolumn{2}{c}{ Nature of Brine Water } \\
\cline { 2 - 3 } & Reservoir Formation Water & Injection Water \\
\hline $\mathrm{pH}$ & 7.5 & 4.3 \\
\hline & Composition $(\mathrm{g} / \mathrm{L})$ & \\
\hline $\mathrm{Ca}^{2+}$ & 0.24 & 0.27 \\
$\mathrm{Mg}^{2+}$ & 0.17 & 0.06 \\
$\mathrm{Na}^{+}$ & 0.23 & 0.76 \\
$\mathrm{~K}^{+}$ & 0.013 & 0.04 \\
$\mathrm{Sr}^{2+}$ & 0.0007 & 0.003 \\
\hline $\mathrm{Cl}^{-}$ & 1.04 & 0.56 \\
$\mathrm{HCO}_{3}{ }^{-}$ & 0.21 & 0.20 \\
$\mathrm{SO}_{4}{ }^{2-}$ & 0.11 & 1.30 \\
\hline Salinity $(\mathrm{g} / \mathrm{L})$ & 1.71 & 0.92 \\
\hline Turbidity (NTU) & 79.8 & 2.00 \\
\hline Dry extract $(\mathrm{g} / \mathrm{L})$ & 3.24 & 4.10 \\
\hline
\end{tabular}

\subsection{Graft-Copolymerization of AAm onto Xanthan}

The reaction synthesis of xanthan-g-polyacrylamide was carried out following the method described by Kumar et al. [25]. In this work microwave irradiation (MW) was exploited (in the presence and absence of APS initiator) to produce free radical sites on the polymer surface. Briefly, the desired amount of xanthan was dispersed in deionized water and stirred overnight. To this solution, a known amount of acrylamide was added, and the mixture was stirred until complete dissolution; for the grafting in the presence of redox initiator, a known amount of APS was included to this above solution. The so prepared solution was irradiated in a domestic microwave oven (Philips Whirlpool Model AVM 581), by varying the procedure parameters (time, power, concentration of AAm and xanthan amount) in order to prepare a range of grafted xanthan samples. After reaction, the grafted samples were washed first with acetone, then with a mixture of methanol-water to extract any unreacted monomer residues. Solid precipitates obtained were submitted to filtration and drying overnight under vacuum at $40^{\circ} \mathrm{C}$, then ground into powder and finally weighed up and kept steady in a desiccator. The grafting ratio $(G \%)$, grafting efficiency $(G E \%)$ and homopolymer fraction $(H \%)$ were calculated using the following equations:

$$
\begin{gathered}
(\% G)=\left(\frac{W_{1}-W_{0}}{W_{0}}\right) \cdot 100 \\
(\% G E)=\left(\frac{W_{1}-W_{0}}{W_{2}}\right) \cdot 100 \\
(\% H)=100-(\% G E)
\end{gathered}
$$

where $W_{0}$ is the weight of xanthan, $W_{1}$ the weight of graft copolymer, and $W_{2}$ the weight of acrylamide.

\subsection{Solubility Tests}

The main condition for using a polymer in EOR is the water-solubility. Solubility of grafted copolymers was tested in three different fluids: deionized water, injection, and formation brines. Suitable amounts of polymer powder were dissolved in the corresponding medium by stirring at room temperature. From the solubility test results, it was observed that all grafted samples were dissolved in a few minutes (3-5 $\mathrm{min})$ in the three fluids. All graft copolymers were easily and completely soluble. After three weeks of storage in de-aerated conditions, they were still stable. 


\subsection{Preparation of Polymer Solutions}

Xanthan and xanthan-g-polyacrylamide solutions at 500, 1000 and 2000 ppm concentrations were prepared in DW, IW and RW respectively. Polymer solutions examined for rheological experiments were fresh samples. For this purpose, suitable amounts of polymer were dissolved into the specific fluid under stirring in a paddle mixer. Here, we have taken some precautions. The polymer was gradually incorporated into the mixer containing the solvent under strong mixing. After a few minutes, the stirring speed was reduced, and the solution was gently stirred overnight for complete dissolution of polymer powder. Lastly, the solution was collected and stored under vacuum.

\subsection{FTIR Characterization}

Grafting was evidenced by infrared spectroscopic analysis. The IR spectra of xanthan, polyacrylamide and xanthan-g-polyacrylamide were performed on a Thermo Scientific Nicolet IS 10 apparatus equipped with an ATR element (Smart iTR). Measurements were completed under a protocol of 40 scans and $2 \mathrm{~cm}^{-1}$ determination, over wavenumber extent from 4000 to $600 \mathrm{~cm}^{-1}$.

\subsection{Rheology of Polymer Solutions}

Xanthan and grafted xanthan rheology analysis was done under controlled shear rate with T.A. Instruments AR-2000 rheometer. Polymer flow was examined using Couette cell geometry with a $1 \mathrm{~mm}$ gap between the coaxial cylinders, to prevent solvent evaporation during the tests; a trap is set up on the cell. Steady shear tests were conducted over a shear rate limit of $0.1-400 \mathrm{~s}^{-1}$ (this covers the shear rate values ranged between 1 and $15 \mathrm{~s}^{-1}$ admitted away from the wellbore of the studied reservoir). Indeed, for the flow settings of most reservoirs, the average shear rate from the injection well was normalized to $1-20 \mathrm{~s}^{-1}[26,27]$. For dynamic oscillatory shear, the frequency sweep tests were done in the linear viscoelastic regime over a frequency from 0.1 to $100 \mathrm{rad} / \mathrm{s}$ at $25^{\circ} \mathrm{C}$ and constant oscillating stress. Prior to frequency sweep experiments, a preliminary stress sweep test was done to fix the linear viscoelastic domain of polymer solutions.

\section{Results}

\subsection{Influence of Grafting Reaction Conditions}

During grafting, functionalized acrylamide reacts with the backbone xanthan to form xanthan-g-polyacrylamide. The graft copolymerization can be initiated either by conventional chemical treatment or by ionizing radiation. Under microwaves, graft copolymerization appears more selective and productive, the reaction results in high grafting efficiency. With conventional methods, the competing homopolymerization lowers the grafting yields [28,29]. Here, the proposed mechanism on polymer is that the polar reactive $\mathrm{CH}_{2}-\mathrm{OH}$ adjacent groups on the xanthan backbone absorb the MW energy and dissociate, thus producing a macro radical onto the polymer chain. On APS initiator, the initiation mechanism is that MW heating generates dissociation of persulfate and formation of sulfate ion free radicals $\left(\mathrm{SO}_{4} \bullet\right)$, which on reaction with water gives $\bullet \mathrm{OH}$ free radicals. Next, $\mathrm{SO}_{4} \bullet-$ and $\bullet \mathrm{OH}$ free radicals attack the xanthan macromolecule resulting in the formation of macroradicals on the xanthan backbone. The Xan-O• macroradicals react with AAm monomer and generate XG-based AAm free radicals. The activated monomer subsequently reacts with another monomer and propagates the chain reaction, stemming graft copolymer. Alternately, the $\bullet \mathrm{OH}$ free radicals may react with monomer and generate monomer free radicals. The activated monomer subsequently reacts with free radical sites of xanthan stemming graft copolymer. In this work, the microwave-assisted grafting reaction was achieved with and without initiator. As expected, from the results of Table 2 it can be observed that graft copolymerization in the presence of chemical initiator provided higher grafting parameters. 
Table 2. Effect of APS initiator on grafting parameters (power $=750 \mathrm{Watt} ; \mathrm{t}=100 \mathrm{~s} ; \mathrm{mXan}=0.2 \mathrm{~g} / \mathrm{L}$; $\mathrm{mAAm}=8.0 \mathrm{mmol}$ ).

\begin{tabular}{cccc}
\hline Grafting Method & $\boldsymbol{G}(\mathbf{\%})$ & $\boldsymbol{G E}(\mathbf{\%})$ & $\boldsymbol{H}(\mathbf{\%})$ \\
\hline In the presence of APS & 269.00 & 94.72 & 5.28 \\
\hline In the absence of APS & 228.50 & 80.45 & 19.55 \\
\hline
\end{tabular}

The optimal conditions that ensure the most effective grafting parameters have been established by optimizing the reaction with respect to xanthan and acrylamide concentration, to power and time of irradiation; in this way ranges of graft copolymers were prepared. Depending on the xanthan amount and acrylamide monomer concentration, Table 3 shows that grafting parameters are increased with the increase in monomer concentration.

Table 3. Effect of monomer concentration on grafting parameters (power $=750 \mathrm{Watt} ; \mathrm{t}=100 \mathrm{~s}$; $\operatorname{mxan}=0.2 \mathrm{~g} / \mathrm{L})$.

\begin{tabular}{cccc}
\hline AAm Concentration $(\mathbf{m m o l})$ & $\boldsymbol{G} \mathbf{( \% )}$ & $\boldsymbol{G E} \mathbf{( \% )}$ & $\boldsymbol{H} \mathbf{( \% )}$ \\
\hline 2.50 & 48.00 & 57.14 & 42.86 \\
3.80 & 81.00 & 60.44 & 39.55 \\
5.20 & 200.50 & 85.68 & 14.32 \\
6.60 & 203.50 & 86.96 & 13.03 \\
8.00 & 269.00 & 94.72 & 5.28 \\
10.80 & 235.00 & 87.23 & 12.76 \\
\hline
\end{tabular}

In contrast, from Table 4, the grafting parameters are independent of the xanthan amount.

Table 4. Effect of xanthan amount on grafting parameters (Power $=750$ Watt; $t=100 \mathrm{~s}$; $\mathrm{mAAm}=8.0 \mathrm{mmol}$ ).

\begin{tabular}{cccc}
\hline Xanthan Amount $(\mathrm{g} / \mathbf{L})$ & $\boldsymbol{G} \mathbf{( \% )}$ & $\boldsymbol{G E} \mathbf{( \% )}$ & $\boldsymbol{H} \mathbf{( \% )}$ \\
\hline 0.10 & 505.00 & 88.90 & 11.10 \\
0.15 & 356.66 & 94.19 & 5.81 \\
0.20 & 269.00 & 94.71 & 5.28 \\
0.25 & 191.20 & 75.35 & 24.65 \\
0.30 & 135.33 & 71.47 & 28.53 \\
0.35 & 62.28 & 38.38 & 61.62 \\
\hline
\end{tabular}

From the results in Tables 5 and 6, it can be observed that when the power and time of irradiation are increased, there occurs a corresponding increase in percentage grafting and grafting efficiency, whereas homopolymer formation reduces. The concentration of APS initiator was kept to $0.22 \mathrm{~g} / \mathrm{L}$ for all sets of experiments.

Table 5. Effect of irradiation power on grafting parameters $(t=100 \mathrm{~s} ;$; $m$ xan $=0.2 \mathrm{~g} / \mathrm{L}$; $\mathrm{mAAm}=8.0 \mathrm{mmol}$ ).

\begin{tabular}{cccc}
\hline Power (Watt) & $\boldsymbol{G} \mathbf{( \% )}$ & $\boldsymbol{G E} \mathbf{( \% )}$ & $\boldsymbol{H} \mathbf{( \% )}$ \\
\hline 150 & 101.00 & 35.56 & 64.43 \\
350 & 116.50 & 41.02 & 59.00 \\
500 & 166.50 & 58.62 & 41.38 \\
650 & 245.50 & 86.44 & 13.56 \\
750 & 269.00 & 94.72 & 5.28 \\
\hline
\end{tabular}


Table 6. Effect of irradiation time on grafting parameters (Power $=750 \mathrm{Watt}$; $\mathrm{mxan}=0.2 \mathrm{~g} / \mathrm{L}$; $\mathrm{mAAm}=8.0 \mathrm{mmol}$ ).

\begin{tabular}{cccc}
\hline Time (s) & $G \mathbf{~ ( \% )}$ & $G E \mathbf{~ \% )}$ & $H(\mathbf{\%})$ \\
\hline 30 & 130.50 & 45.95 & 54.05 \\
40 & 180.50 & 63.55 & 36.45 \\
50 & 228.50 & 80.45 & 19.55 \\
100 & 269.00 & 94.72 & 5.28 \\
150 & 281.50 & 99.11 & 0.88 \\
200 & 277.50 & 97.71 & 2.29 \\
\hline
\end{tabular}

Lastly, for an effective graft copolymerization reaction, the optimized settings adopted are: Xanthan conc. $=0.2 \mathrm{~g} / \mathrm{L} ;$ AAm conc. $=8.0 \mathrm{mmol}$; Power $=750$ watts; Irradiation Time $=100 \mathrm{~s}$. With these settings, the best grafting parameters are obtained as following: $G(\%)=269.00 \%$; GE $(\%)=94.72 \% ; H(\%)=5.28 \%$.

\subsection{Polymers Characterization}

\section{FTIR Characterization}

Polymers FTIR spectra are shown in Figure 1.

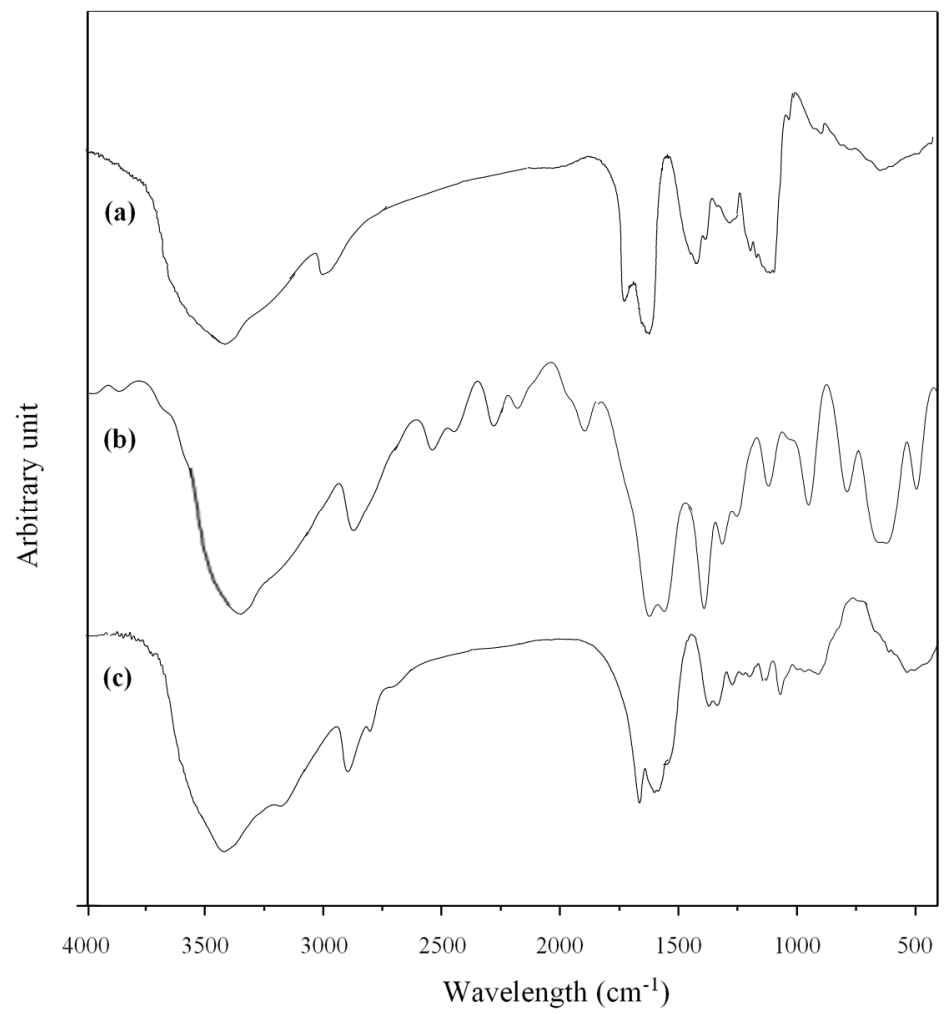

Figure 1. FTIR spectra of xanthan (a), polyacrylamide (b) and xanthan-g-polyacrylamide (c).

For xanthan (Figure 1a) the spectrum displays a characteristic broad band at $3410 \mathrm{~cm}^{-1}$ assigned to elongation of hydroxyl group. Peaks at $1735 \mathrm{~cm}^{-1}$ and $1628 \mathrm{~cm}^{-1}$ are ascribed to the $\mathrm{C}-\mathrm{O}$ vibration of alkyl esters and asymmetrical stretching of carboxylate, respectively. Further specific bands of xanthan that appear at $1410 \mathrm{~cm}^{-1}$ and $1065 \mathrm{~cm}^{-1}$ are assigned to $\mathrm{C}-\mathrm{H}$ bending of methyl group and $\mathrm{C}-\mathrm{O}$ stretching of alcohol, respectively.

Polyacrylamide spectrum (Figure 1b) first presents two bands at $3375 \mathrm{~cm}^{-1}$ and $3185 \mathrm{~cm}^{-1}$ allocated to asymmetrical and symmetrical elongation of $\mathrm{N}-\mathrm{H}$ bond. A specific band of $\mathrm{C}-\mathrm{H}$ stretching bonds appears then at $2880 \mathrm{~cm}^{-1}$. Characteristic bands of firstamide (C-O elongation) and second-amide ( $\mathrm{N}-\mathrm{H}$ bending) are displayed at $1670 \mathrm{~cm}^{-1}$ 
and $1610 \mathrm{~cm}^{-1}$. The peak at $1410 \mathrm{~cm}^{-1}$ refers to elongation of $C-N$, while that at $960 \mathrm{~cm}^{-1}$ is related to the $\mathrm{C}-\mathrm{H}$ bending out of plane. As expected, xanthan-g-polyacrylamide copolymer exhibited a combination of the absorption bands of xanthan and polyacrylamide, indicating that grafting was successful (Figure 1c). The broad band displayed at $3420 \mathrm{~cm}^{-1}$ is related with the overlap between the stretching bands of $\mathrm{N}-\mathrm{H}$ amide group and $\mathrm{O}-\mathrm{H}$ of xanthan. The band at $1675 \mathrm{~cm}^{-1}$ is related to superposition bands of amide-I (C-O elongation) and asymmetrical $\mathrm{C}-\mathrm{O}$ stretching of carboxylate amide group. The peak at $1615 \mathrm{~cm}^{-1}$ is assigned to amide-II (NH bending) band of amide group. Additionally, at $1410 \mathrm{~cm}^{-1}$, the broad absorption band results from the overlay of the $\mathrm{C}-\mathrm{H}$ bending band of xanthan methyl group and the $\mathrm{C}-\mathrm{N}$ stretching band of polyacrylamide.

\subsection{Rheological Analysis}

The flow behavior of polymer solutions changes in shear viscosity under temperature and reservoir salinity and viscoelastic properties of these solutions are all sensitive parameters to describe the interface of oil/polymer solution system. As part of our main objective, polymer flooding ability of xanthan and grafted xanthan solutions has been studied in terms of their performance under various steady and oscillatory shear environments and conditions.

\subsubsection{Steady Shear Viscosity of Xanthan and Grafted Xanthan Solutions}

In the first part, evolution of shear viscosity of the prepared polymer solutions was reported in relation with polymer concentration, temperature and brine nature. In the literature, the flow behavior of xanthan was reviewed very well; it has been shown that xanthan solutions exhibited pseudoplastic behavior with shear-thinning character. Furthermore, values of apparent viscosity were most often correlated by the power law equation throughout a broad array of shear rates. The xanthan solutions offer a significant performance in salt resistance but are deficient in elasticity and their application is limited in the high temperature reservoirs. To prevail over these shortcomings, some attempts are made to improve the behavior of xanthan solutions in the high temperature reservoirs. For this purpose, the approach that was adopted in this work consists of the graft copolymerization of acrylamide onto xanthan to produce graft copolymers with improved viscoelastic properties. Experimental results of the apparent viscosity changes (Pa.s) with shear rate $\left(\mathrm{s}^{-1}\right)$ are displayed in Figure 2A for xanthan and Figure 2B for xanthan-g-polyacrylamide, respectively. Polymer concentrations used are of 500, 1000 and $2000 \mathrm{ppm}$.

In the region of very low rates, apparent viscosity does not change much, and then begins to drop sharply. This non-Newtonian shear-thinning behavior was expected for this kind of polymer. As seen in Figure 2, at all shear rates, the apparent viscosity is directly proportional to polymer concentration; for a fixed concentration, viscosity is reduced as shear rate is increased.

Values of initial viscosity $\left(\eta_{0}\right)$ at zero-shear rate are significantly boosted with increase in polymer concentration; this rise is particularly obvious in the low shear rate region $\left(<10 \mathrm{~s}^{-1}\right)$. At higher shear rates, the difference in viscosity values between the three concentrations becomes narrower. In the plotted curves of Figure 2, viscosity changes of polymer solutions show initially a Newtonian flow in the zone of very low shear rates; over this limited shear range, the value of $\eta_{0}$ remains constant. Afterwards, as shear rate increases, a shear-thinning region takes place. In this zone, apparent viscosity of polymer solutions reduces according to a power law and subsequently moves to a limiting value of infinite-shear viscosity $\left(\eta_{0}\right)$. At the start of shearing, at low rates, macromolecular chains are entangled, and so in these conditions the high viscosity of solutions is due the resistance to flow. As the shear rate increases gradually, the aggregates formed by these entanglements are broken and macromolecules organize along the flow direction; at this time the flow resistance decreases and leads to a drop in viscosity. As seen from the plots, shear thinning of solutions was conserved at all polymer concentrations. At intermediate concentration (1000 ppm), both polymers show a minor viscosity loss, which can be relatively easy to 
recover. However, at low concentration (500 ppm), the loss is very important, and it seems that at this level the grafted xanthan with less loss behaves better than xanthan.
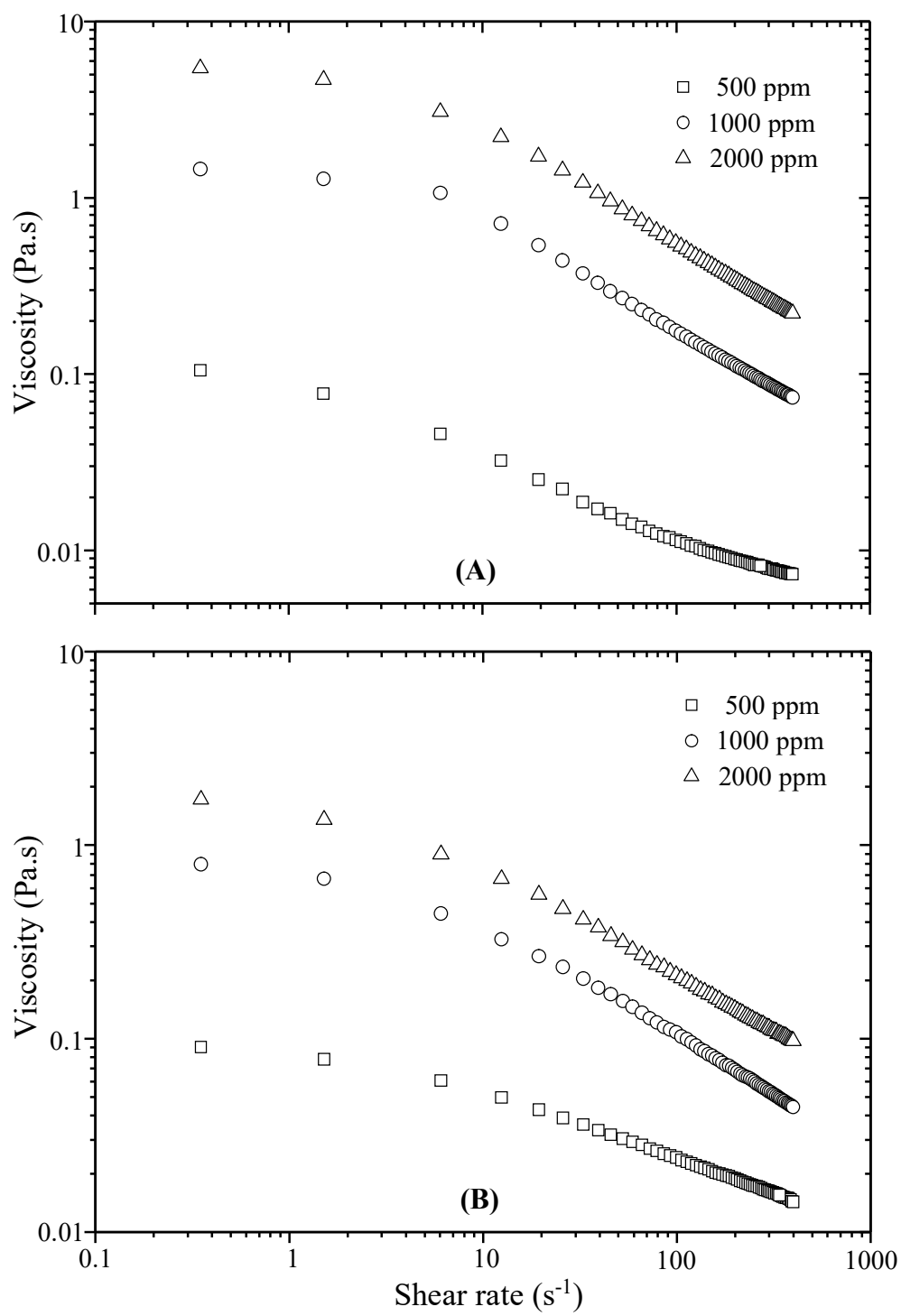

Figure 2. Influence of polymer concentration on shear viscosity for xanthan (A) and grafted xanthan (B)-deionized water solutions.

Finally, it can then be said that the concentration of polymer is a key factor to increase the shear viscosity. Consequently, this increase in viscosity can adjust the poor water/oil mobility ratio responsible for poor water flood performance. Therefore, in our subsequent rheological studies the recommended concentration used for polymer solutions was fixed to $2000 \mathrm{ppm}$. Moreover, in order to improve the sweep efficiency, all EOR techniques suggest a strict control of shear viscosity of solutions at the wellbore under oilfield conditions, i.e., salinity or temperature. In many oil fields, deposit water below the hydrocarbons is usually salty; the presence of high concentrations of sodium chloride and divalent ions affects the polymer behavior during flooding. For example, at high salinity, xanthan polymer seems less sensitive to mechanical shear because of its rigid rod-like conformation. Contrastingly, synthetic polymers used in EOR (i.e., polyacrylamides) are affected by the aqueous phase salinity because of the screening effect of charged polymer chains. Accordingly, resistance to shearing of polyacrylamide solutions in brines becomes a significant parameter for their eligibility for polymer flooding. In most cases, the shear degradation under salts occurs at different levels governed by polymer type [30]. From this perspective, it will be interesting 
to examine the influence of injection or reservoir water on the shear viscosity of the grafted copolymer. As for xanthan, the influence of salts will be decisive on the viscosity of the grafted xanthan. In Figure 3, we report the evolution of apparent viscosity on shear rate for xanthan-brines (Figure 3A) and for grafted xanthan-brine systems (Figure 3B).

As seen in the Figures, the shear thinning of both polymer solutions is conserved in the presence of brines; moreover, viscosity losses in saline solutions are better controlled in grafted xanthan solutions. Data from viscosity-shear rate function are usually fitted by some flow equations; among those the power law equivalence covers only a limited array of shear rates; indeed, low-shear $\left(\eta_{0}\right)$ and very high-shear $\left(\eta_{\infty}\right)$ ranges are poorly fitted. The Cross model (Equation (4)) covers the entire shear rate range; it was developed to clarify viscosity behavior of non-Newtonian fluids [31,32]:

$$
\eta_{a_{F P}}=\eta_{\mathrm{o}}+\frac{\left(\eta_{0}-\eta_{\mathrm{o}}\right)}{\left[1+\left(\alpha_{c} \cdot \dot{\gamma}\right)^{m}\right]}
$$

where $\eta_{\text {app }}$ (Pa.s) is the apparent viscosity of polymer solutions, $\eta_{\infty}$ and $\eta_{0}$ (zero-shear and infinite-shear viscosities) are related to the Newtonian limits of the polymer viscosity in the low and high shear rates, and $\alpha_{c}$ (s) is a constant related to the relaxation time of polymer and $\mathrm{m}$ is a dimensionless exponent. Fit values of Cross parameters are displayed in Table 7 for 2000-ppm polymer solutions.
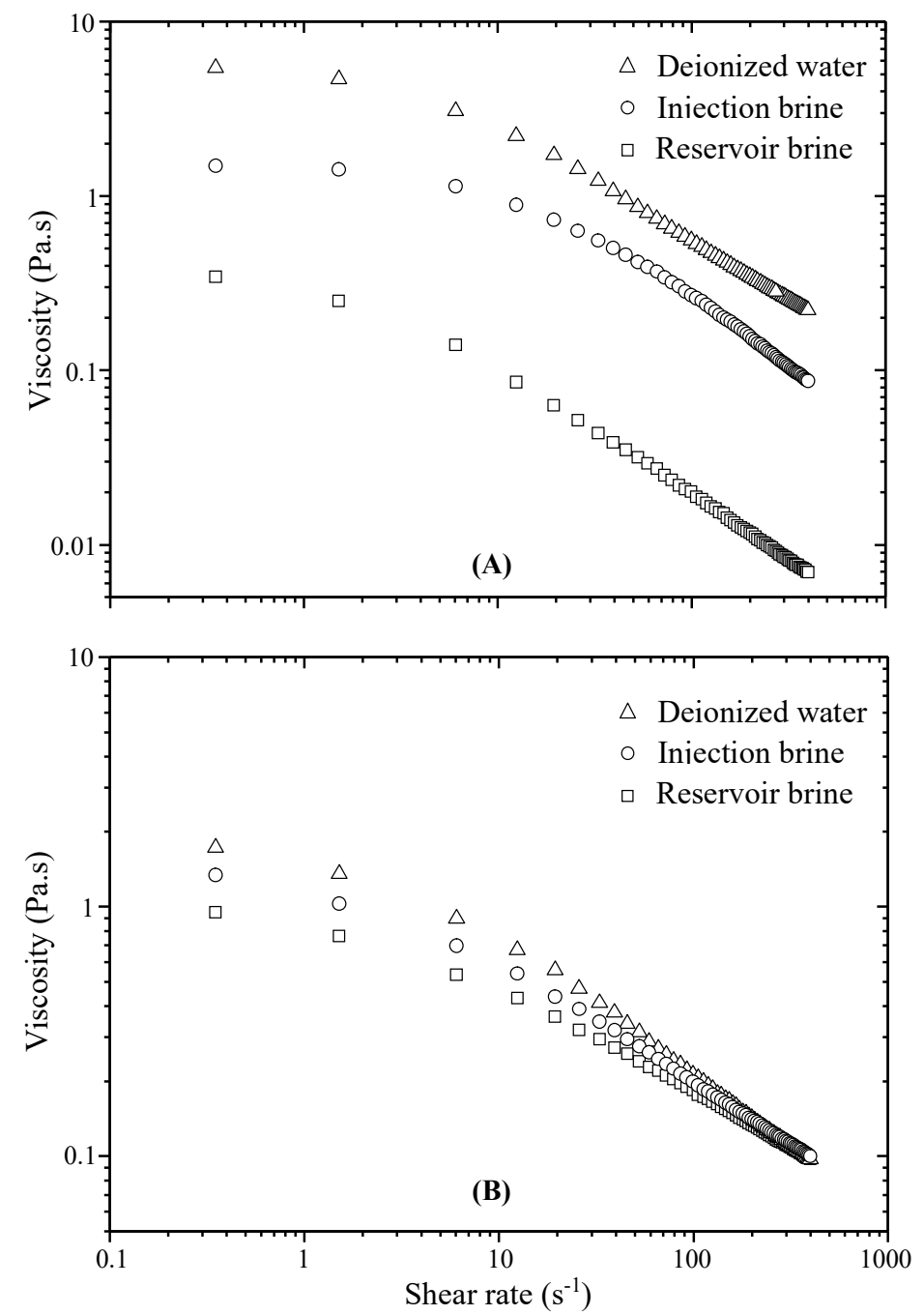

Figure 3. Influence of brine salinity on shear viscosity for xanthan (A) and grafted xanthan-brine solutions (B). (Polymer concentration $=2000$ ppm). 
Table 7. Cross coefficients for $2000 \mathrm{ppm}$ polymer solutions $\left(\mathrm{T}=25^{\circ} \mathrm{C}\right)$.

\begin{tabular}{|c|c|c|c|c|c|}
\hline Polymer & $\eta_{0}$ (Pa.s) & $\eta_{\infty}$ (Pa.s) & $\alpha_{c}(\mathrm{~s})$ & $m$ & $\mathbf{R}^{2}$ \\
\hline \multicolumn{6}{|c|}{ Polymer-deionized water } \\
\hline Xanthan & $5.85 \pm 14.8 \times 10^{-3}$ & $0.077 \pm 3.8 \times 10^{-3}$ & 0.146 & $0.89 \pm 4.7 \times 10^{-3}$ & 0.9999 \\
\hline Grafted xanthan & $2.01 \pm 13.3 \times 10^{-3}$ & $0.010 \pm 2.8 \times 10^{-3}$ & 0.227 & $0.69 \pm 7.1 \times 10^{-3}$ & 0.9997 \\
\hline \multicolumn{6}{|c|}{ Polymer-Injection water } \\
\hline Xanthan & $2.44 \pm 12.3 \times 10^{-3}$ & $0.019 \pm 4.0 \times 10^{-3}$ & 0.116 & $0.86 \pm 9.5 \times 10^{-3}$ & 0.9996 \\
\hline Grafted xanthan & $1.67 \pm 11.1 \times 10^{-3}$ & $0.012 \pm 2.1 \times 10^{-3}$ & 0.297 & $0.60 \pm 5.4 \times 10^{-3}$ & 0.9998 \\
\hline \multicolumn{6}{|c|}{ Polymer-Reservoir water } \\
\hline Xanthan & $0.40 \pm 2.2 \times 10^{-3}$ & $0.0014 \pm 0.25 \times 10^{-3}$ & 0.375 & $0.84 \pm 6.4 \times 10^{-3}$ & 0.9998 \\
\hline Grafted xanthan & $1.18 \pm 5.8 \times 10^{-3}$ & $0.012 \pm 1.5 \times 10^{-3}$ & 0.239 & $0.56 \pm 3.9 \times 10^{-3}$ & 0.9999 \\
\hline
\end{tabular}

As seen, polymer solutions presented a good fit to the Cross equation; $\mathrm{m}$ values tending to 1 indicate that the solutions were significantly shear thinning as salt concentration is decreased; compared to xanthan the grafted xanthan solutions are less shear thinning. Yield stress or zero-shear viscosity noticed for all polymer solutions at low shear rates is proportional to the concentration of polymer solutions and decreases in the presence of salts. In accordance with the nominal injection rates within our specific reservoir $\left(10-15 \mathrm{~s}^{-1}\right)$, critical value of apparent viscosity $\left(\eta_{c r}\right)$ for polymer solutions was considered at a shear rate value of $12.5 \mathrm{~s}^{-1}$. These values are presented in Table 8 for $2000 \mathrm{ppm}$ xanthan and grafted xanthan solutions in the brines used.

Table 8. Viscosity dependence of $2000 \mathrm{ppm}$ polymer solutions at $12.5 \mathrm{~s}^{-1}$ shear rate.

\begin{tabular}{cccc}
\hline Temperature $\left({ }^{\circ} \mathbf{C}\right)$ & \multicolumn{2}{c}{ Viscosity at $\mathbf{1 2 . 5} \mathbf{s}^{-\mathbf{1}}$} & Shear Rate and 2000 ppm Polymer Concentration (Pa.s) \\
\hline & Deionized Water & Injection Brine & Reservoir Brine \\
\hline 25 & 0.671 & 0.540 & 0.430 \\
\hline 45 & 0.119 & 0.245 & 0.208 \\
\hline 65 & 0.065 & 0.184 & 0.166 \\
\hline
\end{tabular}

For grafted xanthan solutions, the values are quite close, which means that the viscosity losses due to salinity are minimal, compared to xanthan solutions. The viscosity loss due to salt degradation $\left(\Phi_{S} \%\right)$ was estimated by the following equation:

$$
\Phi_{s}(\%)=\frac{\eta_{D W}-\eta_{I W}}{\eta_{D W}} .100
$$

where $\eta_{D W}$ (Pa.s) is the viscosity of polymer-deionized water at $12.5 \mathrm{~s}^{-1}$ shear rate and $25^{\circ} \mathrm{C}$; $\eta_{I W}$ (Pa.s) the viscosity of polymer-injection/reservoir water at the same settings. Figure 4 shows the viscosity losses due to salinity at nominal injection rate; thus, for xanthan, the loss reaches approximately $58.3 \%$ for solutions in injection water and $93.2 \%$ in reservoir water. However, these losses were reduced to $16.9 \%$ and $41.3 \%$, respectively, for the grafted xanthan solutions. As an example, for the effect of polymer concentration, at the wellbore nominal injection rate the viscosity loss for xanthan solutions in deionized water was estimated at $67.8 \%$ when the polymer concentration is reduced by half. Another halving boosts dramatically the loss to $98.5 \%$. In comparison, for xanthan-g-polyacrylamide solutions, these losses are lower: they were $51.4 \%$ and $92.6 \%$, respectively. From this, it can then be said that polymer concentration is another key factor to control the shear viscosity. 


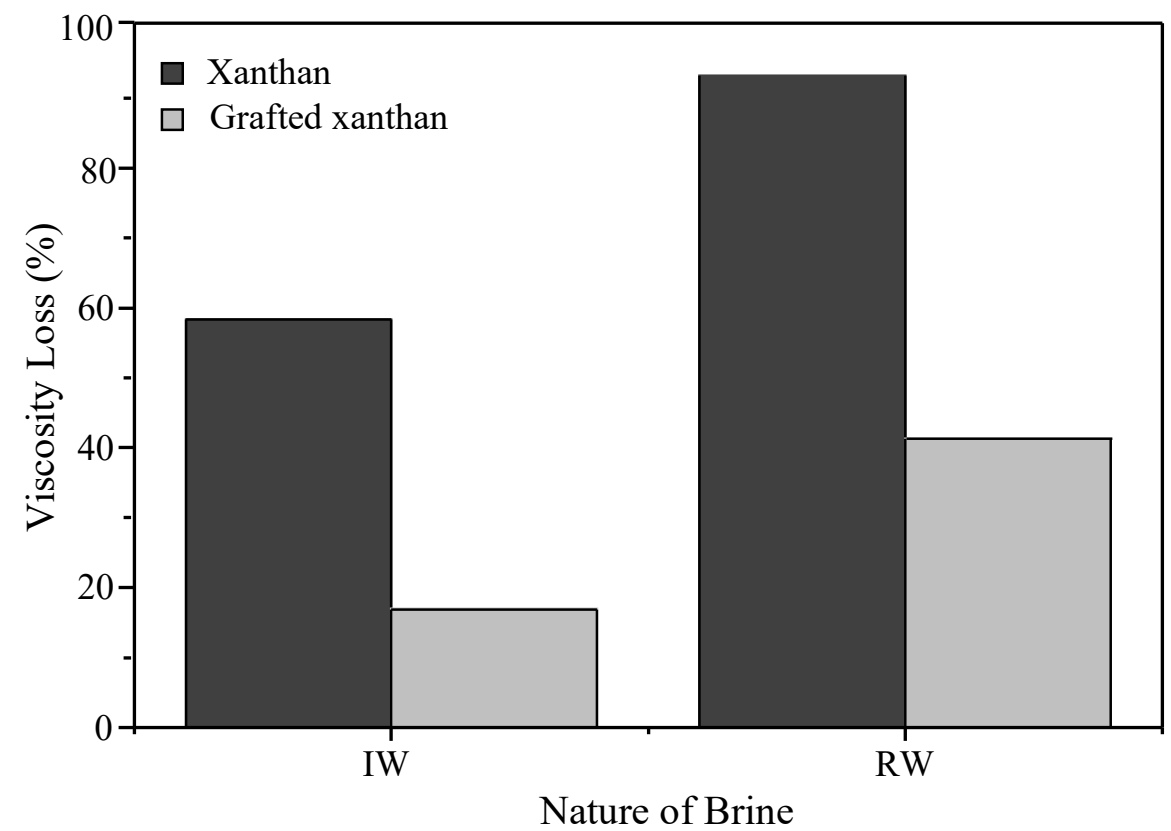

Figure 4. Viscosity loss ratio of polymer-brine solutions.

Influence of temperature on flow behavior of 2000-ppm polymer solutions has been examined at 25,45 and $65^{\circ} \mathrm{C}$; the latter is close to the reservoir temperature of the oil field. Figure 5 for xanthan and Figure 6 for grafted xanthan show the shear rate dependence of apparent viscosity at the three temperatures for solutions in DW (A), in IW (B) and in RW (C). All polymer solutions exhibit a drop in viscosity when the temperature is increased, and this loss is emphasized by the presence of salts. From the Figures, we can also notice that in saline solutions when the temperature is raised to 45 then to $65^{\circ} \mathrm{C}$, all the viscosity values of the grafted xanthan are higher than those of xanthan, thus suggesting that the graft copolymer is more resistant to degradation. This is more evident from Table 8 , if we look at the evolution of $\eta_{c r}$ values with temperature at nominal injection rate. Therefore, at the oil well level, it seems that the degradations due to salinity and temperature generate drastic losses for xanthan viscosity; on the other hand, the viscosity of the grafted polymer appears to be better controlled. 


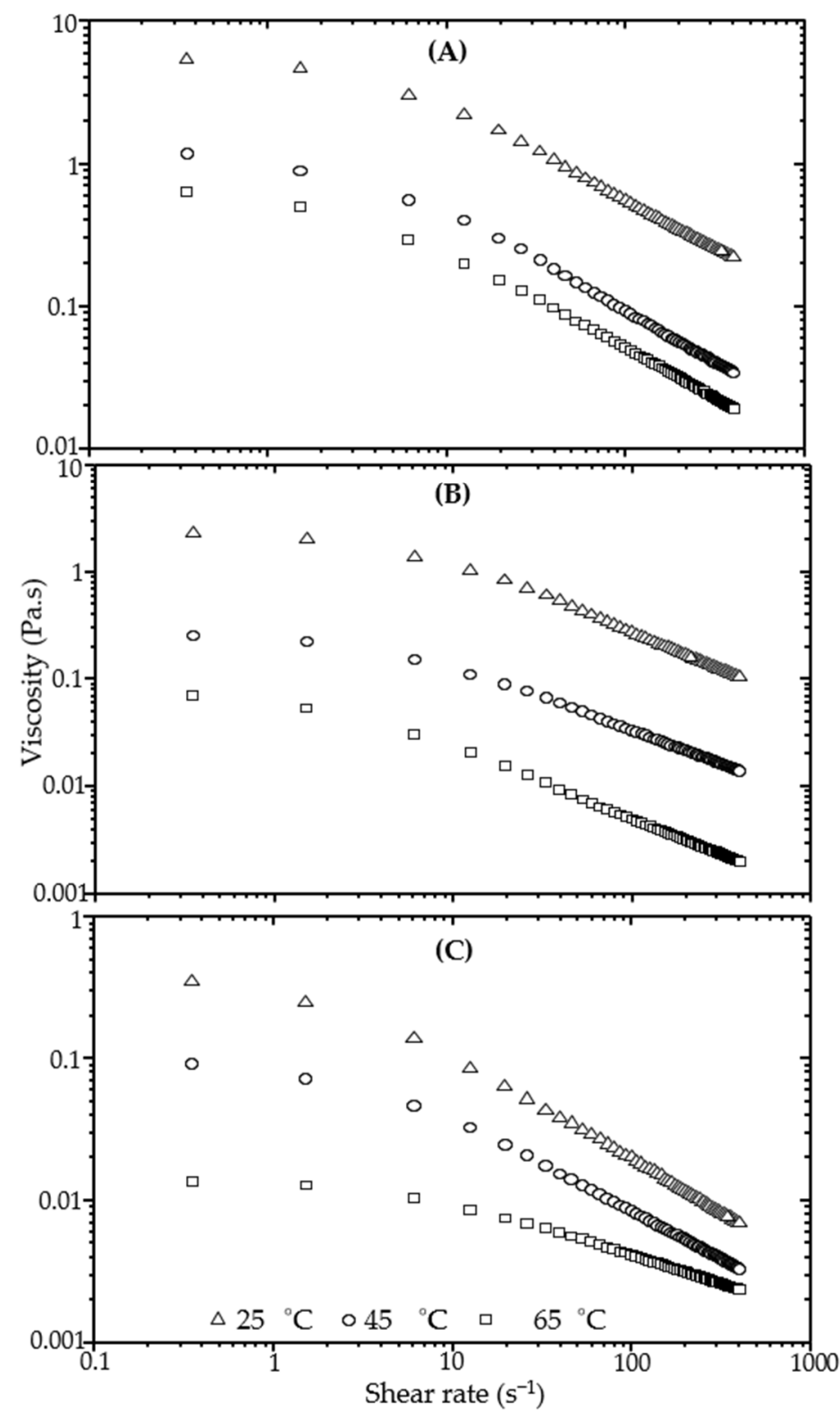

Figure 5. Influence of temperature on shear viscosity of xanthan-DW (A), xanthan-IW (B) and xanthan-RW solutions (C). 


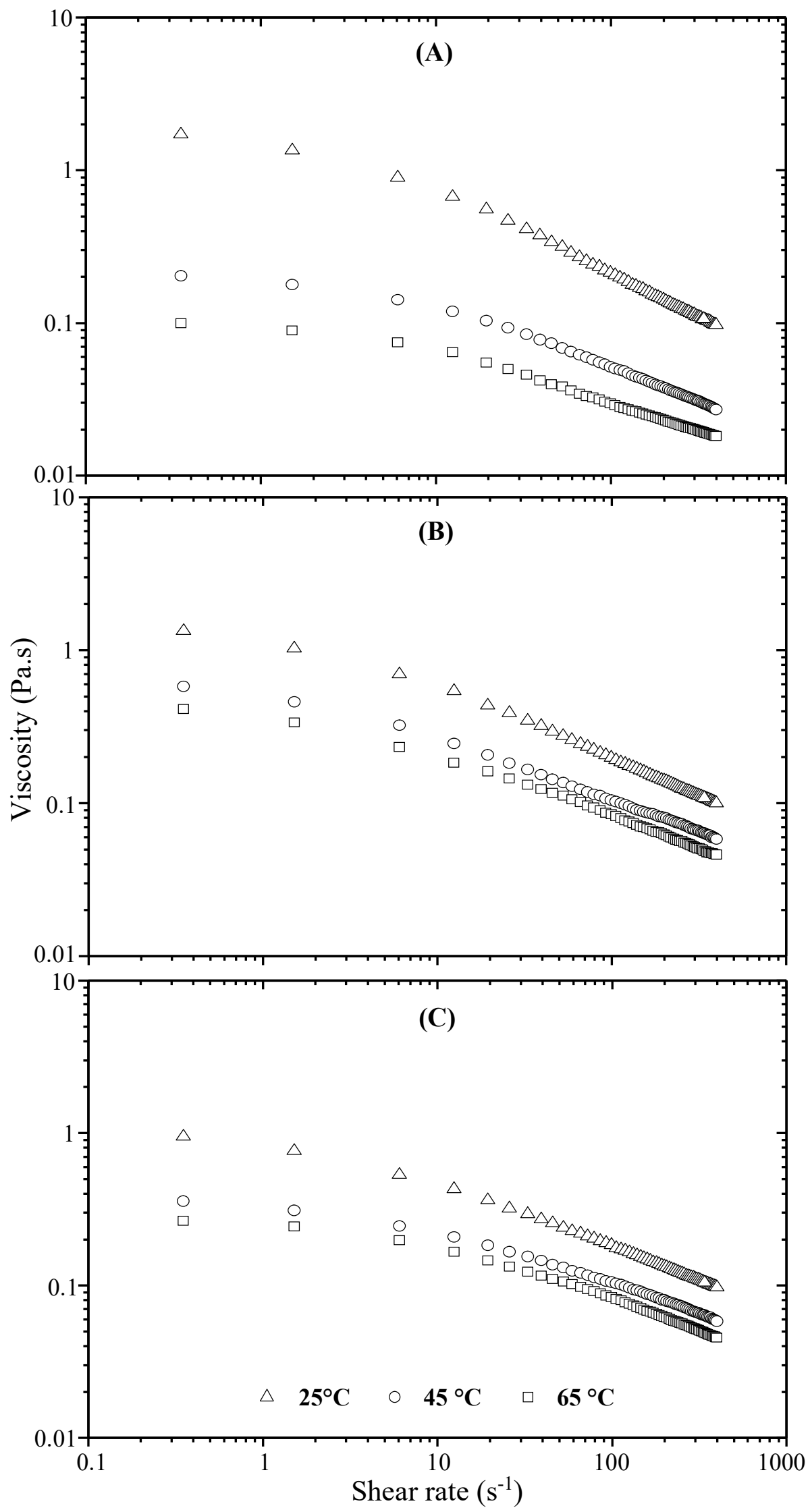

Figure 6. Influence of temperature on shear viscosity of grafted xanthan-DW (A), grafted xanthan-IW (B) and grafted xanthan-RW solutions (C). 
The viscosity loss due to temperature degradation $\Phi_{T}(\%)$ was estimated by the following equation:

$$
\Phi_{T}(\%)=\frac{\eta_{25}-\eta_{T}}{\eta_{25}} .100
$$

Where $\eta_{25}$ (Pa.s) is the viscosity at shear rate of $12.5 \mathrm{~s}^{-1}$ and $25^{\circ} \mathrm{C} ; \eta_{T}$ (Pa.s) the viscosity at the same shear rate and temperatures of $45^{\circ} \mathrm{C}$ then $65^{\circ} \mathrm{C}$. In Figure 7 , we report the losses of polymer viscosity for the temperature rise to $45^{\circ} \mathrm{C}$ (Figure $7 \mathrm{~A}$ ), and further to $65{ }^{\circ} \mathrm{C}$ (Figure 7B).
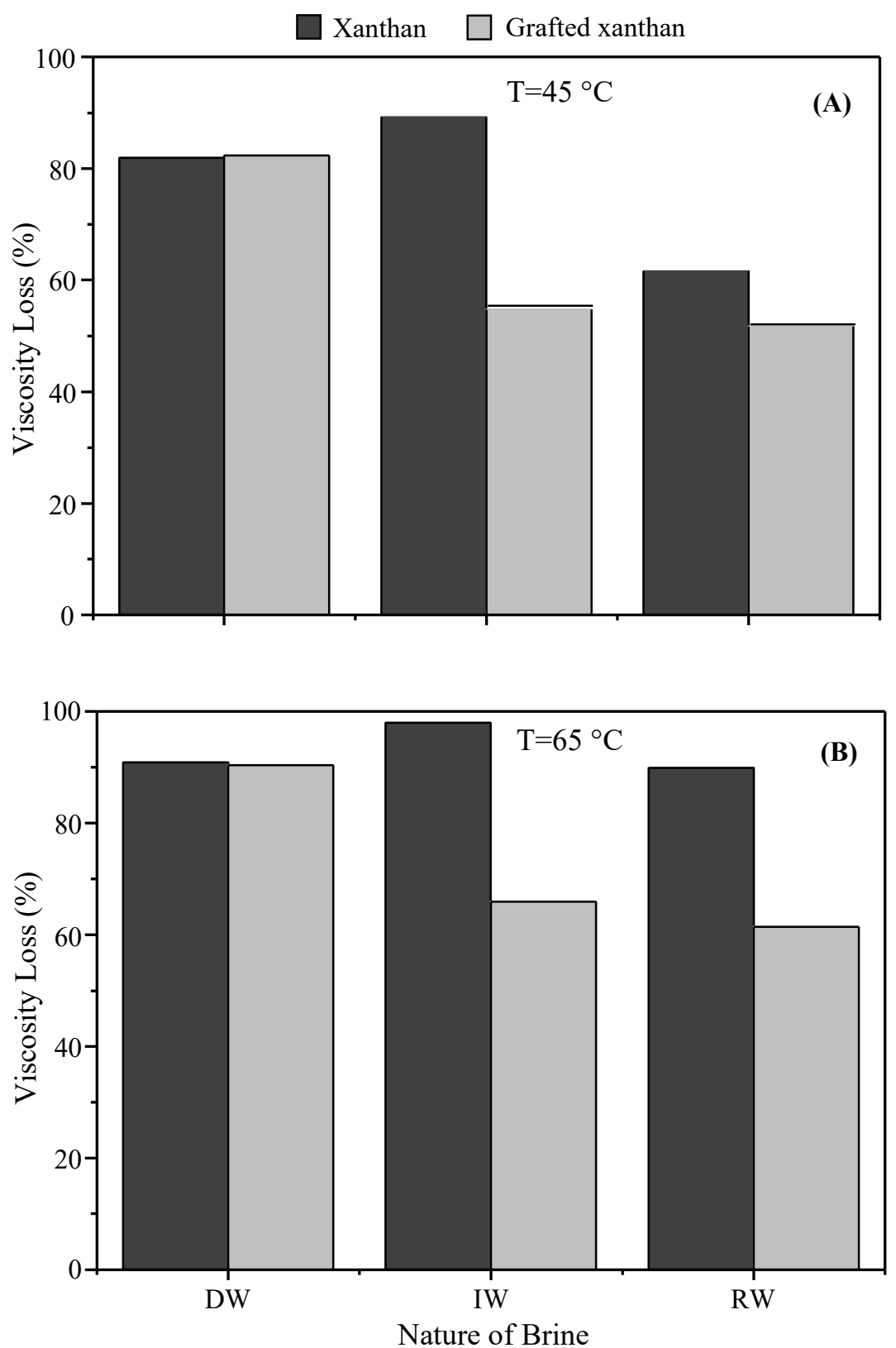

Figure 7. Viscosity loss ratio at $45^{\circ} \mathrm{C}(\mathbf{A})$ and $65^{\circ} \mathrm{C}(\mathbf{B})$ of polymer solutions.

As seen for solutions in deionized water, the viscosity losses due to temperature are extremely high and the same losses are observed for both polymers. Thus, the polymer solutions retain about $18 \%$ of their initial viscosity when the temperature is raised to $45^{\circ} \mathrm{C}$. At around reservoir temperature $\left(65^{\circ} \mathrm{C}\right)$, viscosity loss reaches more than $90 \%$. For solutions in injection water the degradation due to temperature is more critical for xanthan 
solution; thus, for the first temperature rise to $45^{\circ} \mathrm{C}$, xanthan holds only $10 \%$ of its initial viscosity, while at the same time the grafted xanthan solution keeps up more than $45 \%$ of $\eta_{25}$. At $65^{\circ} \mathrm{C}$, viscosity of the xanthan solution is almost completely lost while the grafted xanthan still preserves more than 35\%. Surprisingly, in the brinier reservoir water, the viscosity losses of both polymer solutions are more controlled; this applies especially to the grafted polymer.

\subsubsection{Oscillatory Shear of Grafted Xanthan Solutions}

Besides the shear viscosity, viscoelasticity of the polymer solutions is a significant factor for the choice of suitable polymer for the EOR projects. Usually, highly elastic fluids exhibit notably high-level pressure drop during flow through porous media [33]. Therefore, controlling viscoelastic behavior of injected fluids is an additional key factor in modifying oil-displacing efficiency. Indeed, owing to a suitable elasticity these solutions can drive the remaining oil kept in the porous media [34,35]. Xia et al. observed that polymer solutions with high elastic characteristics could displace residual oil of various natures even without improving the pressure gradient [36].

In the second part of rheological analysis, oscillatory tests have been performed to clarify the dynamic performance of polymer solutions in the linear domain. Oscillatory experiments were carried out with constant stress in the linear limits as defined from the initial stress sweep curves. Viscoelastic properties of polymer solutions are expressed by the elastic and viscous moduli $(\mathrm{Pa})$. The former $\left(\mathrm{G}^{\prime}\right)$ measures the reversible saved energy of the system while the latter $\left(G^{\prime \prime}\right)$ quantifies the energy loss. The viscoelastic characteristics of xanthan solutions in dynamic regime are well known; several works have clarified the behavior of this polysaccharide under oscillatory shear [37]. To our knowledge, dynamic rheology of xanthan-g-polyacrylamide has not yet been studied; an attempt is made here to clarify dynamic behavior of the grafted polymer solutions. Frequency sweeps were conducted for $2000 \mathrm{ppm}$ polymer solutions at $25^{\circ} \mathrm{C}$ and over $0.1-100 \mathrm{Rad} / \mathrm{s}$ of frequency. Figure 8 for xanthan and Figure 9 for grafted xanthan display evolution of $G^{\prime}$ and $G^{\prime \prime}$ according to frequency $(\omega)$ for solutions in DW, IW and RW. To avoid overlapping of the curves, data were vertically shifted by a factor of $10^{\mathrm{a}}$ (with $\mathrm{a}=0,1,2 \ldots$ ). From Figure 8 , the xanthan solution in DW shows behavior of semi-dilute "weak gels". In this state, the individual polymer chains interact, overlap and adopt an expanded coil conformation as expected.

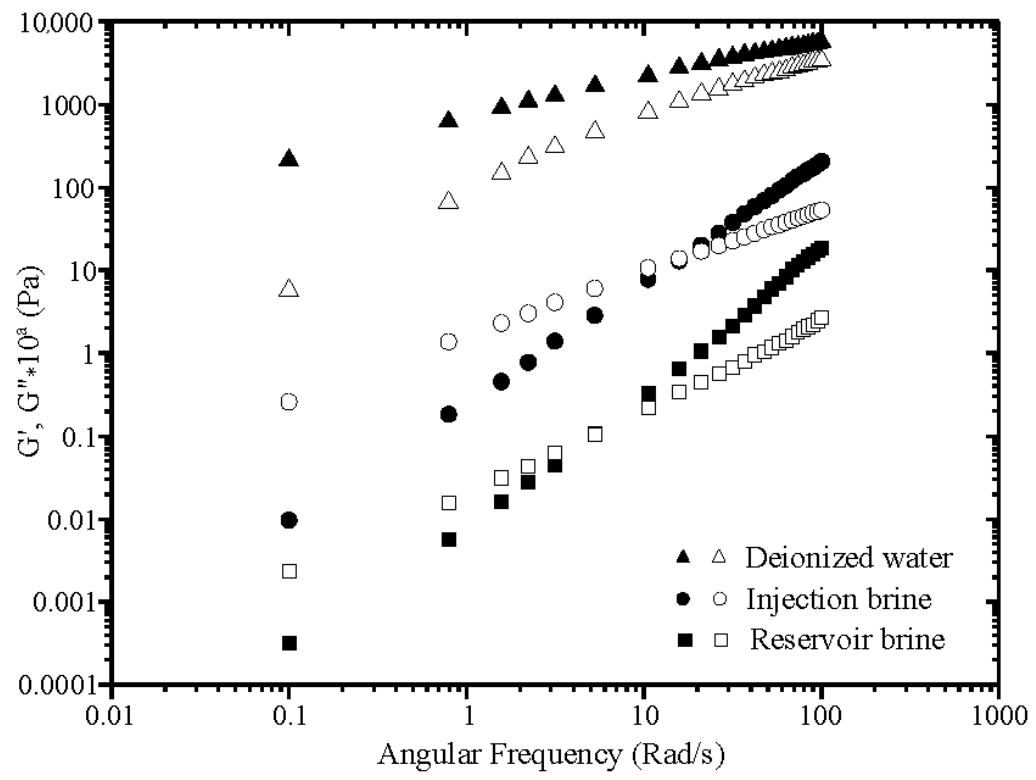

Figure 8. Mechanical spectra of xanthan solutions in DW, IW and RW (filled symbol G', open symbol $\left.\mathrm{G}^{\prime \prime}\right)$. (To avoid overlapping, data have been vertically shifted by $10^{\mathrm{a}}$ with $\mathrm{a}=0,1,2$ ). 


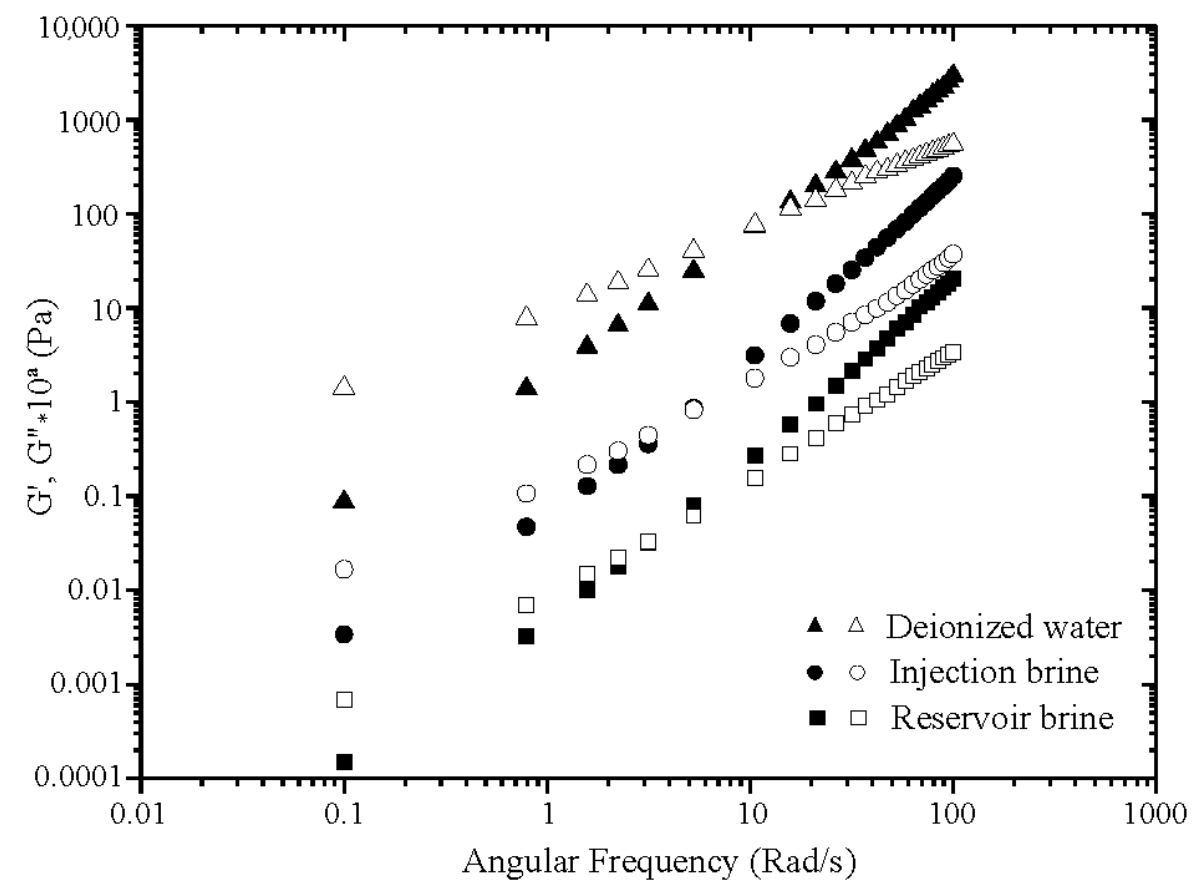

Figure 9. Mechanical spectra of grafted xanthan solutions in DW, IW and RW.

The mechanical spectrum shows that the elastic modulus $G^{\prime}$ remains well above G" over all the applied frequencies, with a weak dependence on frequency for both moduli. An additional dynamic characteristic, the viscoelastic ratio or phase angle $(\delta) \operatorname{tangent}(\tan \delta=$ $G^{\prime \prime} / G^{\prime}$ ) varies from 0.6 to 0.03 in low frequencies, indicating that the elastic nature prevailed over the viscous one. In the brines, IW and RW, xanthan solutions behave as entangled viscoelastic polymers; $G^{\prime}$ and $G^{\prime \prime}$ become more dependent on frequency in the form of $\mathrm{G}^{\prime} \sim \omega^{\mathrm{n}^{\prime}}$ and $\mathrm{G}^{\prime \prime} \sim \omega^{\mathrm{n}^{\prime \prime}}$ with $\mathrm{n}^{\prime}$ and $\mathrm{n}^{\prime \prime}$, slopes of the power dependence. At low frequencies (terminal zone) $G^{\prime \prime}$ exceeds $G^{\prime}$, therefore $G^{\prime}$ crosses $G^{\prime \prime}$, afterward with increasing frequency, value of $G^{\prime}$ becomes larger than that of $G^{\prime \prime}$. The polymer solutions become gradually more elastic with an increase in salinity, as evidenced by the move of the crossover between $G^{\prime}$ and G" to lower frequencies. The shift from the viscous to the prevalent elastic character occurs at a frequency of $15.79 \mathrm{rad} / \mathrm{s}$ for polymer solutions in IW and $5.27 \mathrm{rad} / \mathrm{s}$ for solutions in RW. The drop of crossover frequency in the presence of salts has already been observed for xanthan by Rochefort [38]. In contrast with solutions in DW, $\tan \delta$ varies inversely in IW and RW with low values at high frequencies ( 0.26 and 0.14 , respectively). In Figure 9, the mechanical spectra show that xanthan-g-polyacrylamide solutions behave as semi-dilute entangled systems in the three media and no "weak gel" was formed. The same behavior of that of xanthan in saline solutions is observed: for all polymer solutions $\mathrm{G}^{\prime}$ and $\mathrm{G}^{\prime \prime}$ are frequency dependent. From the values of power law exponents, the frequency dependences of both moduli are of the form $G^{\prime} \sim \omega^{2}$ and $G^{\prime \prime} \sim \omega$. This confirms the behavior of grafted xanthan solutions as fluid-like entanglement networks; at very low frequencies (in the terminal zone), they flow as highly viscous liquids.

For all sample solutions, the values of the parameters n' and n" of frequency power dependence of $G^{\prime}$ and $G^{\prime \prime}$ are summarized in Table 9. 
Table 9. Values of the power dependence of $G^{\prime}$ and $G^{\prime \prime}$ moduli.

\begin{tabular}{|c|c|c|c|c|}
\hline \multirow{2}{*}{ Polymer } & \multicolumn{2}{|c|}{$\mathrm{G}^{\prime}$} & \multicolumn{2}{|c|}{$G^{\prime \prime}$} \\
\hline & $\mathbf{n}^{\prime}$ & $\mathbf{R} 2$ & $\mathrm{n}^{\prime \prime}$ & $\mathbf{R} 2$ \\
\hline \multicolumn{5}{|c|}{ Polymer-deionized water } \\
\hline Xanthan & $0.4 \pm 0.008$ & 0.9960 & $0.6 \pm 0.01$ & 0.9968 \\
\hline Grafted xanthan & $1.8 \pm 0.024$ & 0.9988 & $0.8 \pm 0.01$ & 0.9992 \\
\hline \multicolumn{5}{|c|}{ Polymer-Injection water } \\
\hline Xanthan & $1.4 \pm 0.008$ & 0.9998 & $0.7 \pm 0.003$ & 0.9999 \\
\hline Grafted xanthan & $2.0 \pm 0.012$ & 0.9997 & $1.4 \pm 0.023$ & 0.9984 \\
\hline \multicolumn{5}{|c|}{ Polymer-Reservoir water } \\
\hline Xanthan & $1.8 \pm 0.03$ & 0.9982 & $1.2 \pm 0.02$ & 0.9981 \\
\hline Grafted xanthan & $1.9 \pm 0.02$ & 0.9995 & $1.3 \pm 0.01$ & 0.9997 \\
\hline
\end{tabular}

Compared to xanthan, the elastic properties of xanthan-g-polyacrylamide have been significantly improved in saline media; this enhancement is obviously due to the contribution of the polyacrylamide's chain flexibility. The shift from the viscous to the prevalent elastic character occurs at a crossover frequency of $10.53 \mathrm{rad} / \mathrm{s}$ for polymer solutions in deionized water, $5.27 \mathrm{rad} / \mathrm{s}$ in IW and $3.15 \mathrm{rad} / \mathrm{s}$ for solutions in RW.

\section{Conclusions}

As a potential system to regulate a suitable value of the viscosity needed for drilling fluid applications, xanthan-g-polyacrylamide was synthesized using fast microwaveassisted grafting. The graft copolymer offers an important opportunity to be used for polymer flooding in a specific oil field of geological Devonian nature. For this handling, the grafted xanthan solutions should withstand the particular well nominal injection rates $\left(10-15 \mathrm{~s}^{-1}\right)$, temperature $\left(\sim 68{ }^{\circ} \mathrm{C}\right)$ and salinity of the reservoir water. In search of the optimal conditions that ensure the most effective grafting parameters to produce such a copolymer, the grafting reaction was optimized in terms of reactants' concentration, irradiation power and reaction time. Evidence of grafting has been physico-chemically confirmed by infrared spectroscopy (FTIR). Subsequently, the rheological characteristics of xanthan and grafted xanthan solutions have been studied by varying some key parameters such as concentration, salinity and temperature; results were treated and related with viscosity and elasticity. In all cases, the steady shear viscosity of the polymer solutions exhibited pseudoplastic flow and shear-thinning behavior.

In addition, the viscosity losses of grafted xanthan solutions are more controlled and large parts of these losses due to salinity or temperature have been mostly absorbed. From dynamic measurements, it is demonstrated that the elastic properties of xanthan-gpolyacrylamide have been notably upgraded compared to xanthan. Otherwise, the grafted samples are more stable in the presence of salts and exhibit more elasticity as salinity increases. Therefore, both flow and dynamic experimental results are in good agreement for analyzing the behavior of the grafted xanthan solutions according to polymer concentration, temperature and salinity. Graft-copolymerization of acrylamide onto xanthan gives rise to attractive rheological behaviors in temperature and especially in briny environments. Graft polymer solutions with increased viscosity and elasticity can better control the suitable mobility of the oil/polymer system, which consequently improves the sweep efficiency of the transferring solution. From our perspective, the rheological analysis of xanthan-gpolyacrylamide solutions showed that the prediction for polymer flooding in the particular Devonian oilfield could technically be successful.

Author Contributions: Conceptualization, P.M. and D.A.; methodology, S.C., N.J. and D.A.; formal analysis, N.J. and P.B.; investigation, S.C., P.M. and D.A.; resources, P.M. and D.A.; data curation, S.C. and N.J.; writing—original draft preparation, P.M. and D.A.; writing—review and editing, N.J., P.B. 
and P.M.; supervision, D.A.; project administration, P.M. All authors have read and agreed to the published version of the manuscript.

Funding: This research received no external funding.

Institutional Review Board Statement: Not applicable.

Informed Consent Statement: Not applicable.

Data Availability Statement: The data presented in this study are available on request from the corresponding author.

Conflicts of Interest: The authors declare no conflict of interest.

\section{References}

1. Kamal, M.S.; Sultan, A.S.; Al-Mubaiyedh, U.A.; Hussein, I.A. Review on polymer flooding: Rheology, adsorption, stability, and field applications of various polymer systems. Polym. Rev. 2015, 55, 491-530. [CrossRef]

2. Alvarado, V.; Manrique, E. Enhanced Oil Recovery: An Update Review. Energies 2010, 3, 1529-1575. [CrossRef]

3. Wei, B.; Romero-Zerón, L.; Rodrigue, D. Mechanical Properties and Flow Behavior of Polymers for Enhanced Oil Recovery. J. Macromol. Sci. B 2014, 53, 625-644. [CrossRef]

4. Pope, G.A. Recent Developments and Remaining Challenges of Enhanced Oil Recovery. J. Pet. Technol. 2011, 63, 65-68. [CrossRef]

5. Samanta, A.; Ojha, K.; Sarkar, A.; Mandal, A. Mobility control and enhanced oil recovery using partially hydrolyzed polyacrylamide (PHPA). Int. J. Oil Gas Coal Technol. 2013, 6, 245-258. [CrossRef]

6. Chen, Q.; Wang, Y.; Lu, Z.; Feng, Y. Thermo-viscosifying polymer used for enhanced oil recovery: Rheological behaviors and core flooding test. Polym. Bull. 2013, 70, 391-401. [CrossRef]

7. Levitt, D.B.; Pope, G.A. Selection and Screening of Polymers for Enhanced-Oil Recovery. In Proceedings of the SPE Improved Oil Recovery Symposium, Tulsa, OK, USA, 19-23 April 2008. SPE-113845-MS.

8. Rostami, A.; Kalantari-Meybodi, M.; Karimi, M.; Tatar, A.; Mohammadi, A.-H. Efficient estimation of hydrolyzed polyacrylamide (HPAM) solution viscosity for enhanced oil recovery process by polymer flooding. Oil Gas Sci. Technol. 2018, 73, 22. [CrossRef]

9. Dang, T.Q.C.; Chen, Z.; Nguyen, T.B.N.; Bae, W. Rheological Modeling and Numerical Simulation of HPAM Polymer Viscosity in Porous Media. Energy Source Part A 2015, 37, 2189-2197. [CrossRef]

10. Zhong, L.; Oostrom, M.; Truex, M.J.; Vermeul, V.R.; Szecsody, J.E. Rheological behavior of xanthan gum solution related to shear thinning fluid delivery for subsurface remediation. J. Hazard. Mater. 2013, 244-245, 160-170. [CrossRef]

11. Wever, D.A.Z.; Picchioni, F.; Broekhuis, A.A. Polymers for enhanced oil recovery: A paradigm for structure-property relationship in aqueous solution. Prog. Polym. Sci. 2011, 36, 1558-1628. [CrossRef]

12. Sabhapondit, A.; Borthakur, A.; Haque, I. Characterization of acrylamide polymers for enhanced oil recovery. J. Appl. Polym. Sci. 2003, 87, 1869-1878. [CrossRef]

13. Samanta, A.; Bera, A.; Ojha, K.; Mandal, A. Effects of alkali, salts, and surfactant on rheological behavior of partially hydrolyzed polyacrylamide solutions. J. Chem. Eng. Data 2010, 55, 4315-4322. [CrossRef]

14. Agi, A.; Junin, R.; Gbonhinbor, J.; Onyekonwu, M. Natural polymer flow behaviour in porous media for enhanced oil recovery applications: A review. J. Pet. Explor. Prod. Technol. 2018, 8, 1349-1362. [CrossRef]

15. Jang, H.Y.; Zhang, K.; Chon, B.H.; Choi, H.J. Enhanced oil recovery performance and viscosity characteristics of polysaccharide xanthan gum solution. J. Ind. Eng. Chem. 2015, 21, 741-745. [CrossRef]

16. Choppe, E.; Puaud, F.; Nicolai, T.; Benyahia, L. Rheology of xanthan solutions as a function of temperature, concentration and ionic strength. Carbohydr. Polym. 2010, 82, 1228-1235. [CrossRef]

17. Zhong, C.; Luo, P.; Ye, Z.; Chen, H. Characterization and solution properties of a novel water-soluble terpolymer for enhanced oil recovery. Polym. Bull. 2009, 62, 79-89. [CrossRef]

18. Zolfaghari, R.; Katbab, A.A.; Nabavizadeh, J.; Tabasi, R.Y.; Nejad, M.H. Preparation and characterization of nanocomposite hydrogels based on polyacrylamide for enhanced oil recovery applications. J. Appl. Polym. Sci. 2006, 100, 2096-2103. [CrossRef]

19. Sadicoff, B.L.; Brandão, E.M.; Lucas, E.F. Rheological behaviour of poly(acrylamide-g-propylene oxide) solutions: Effect of hydrophobic content, temperature and salt addition. Int. J. Polym. Mater. 2000, 47, 399-406. [CrossRef]

20. Li, Q.; Wei, B.; Lu, L.; Li, Y.; Wen, Y.; Pu, W.; Li, H.; Wang, C. Investigation of physical properties and displacement mechanisms of surface-grafted nano-cellulose fluids for enhanced oil recovery. Fuel 2017, 207, 352-364. [CrossRef]

21. Xu, L.; Xu, G.; Liu, T.; Chen, Y.; Gong, H. The comparison of rheological properties of aqueous welan gum and xanthan gum solutions. Carbohydr. Polym. 2013, 92, 516-522. [CrossRef]

22. Alquraishi, A.A.; Alsewailem, F.D. Xanthan and guar polymer solutions for water shut off in high salinity reservoirs. Carbohydr. Polym. 2012, 88, 859-863. [CrossRef]

23. Kjøniksen, A.L.; Beheshti, N.; Kotlar, H.K.; Zhu, K.; Nyström, B. Modified polysaccharides for use in enhanced oil recovery applications. Eur. Polym. J. 2008, 44, 959-967. [CrossRef]

24. Ghoumrassi-barr, S.; Aliouche, D. A rheological study of xanthan polymer for enhanced oil recovery. J. Macromol. Sci. B 2016, 55, 793-809. [CrossRef] 
25. Kumar, A.; Singh, K.; Ahuja, M. Xanthan-g-poly(acrylamide): Microwave-assisted synthesis, characterization and in vitro release behavior. Carbohydr. Polym. 2009, 76, 261-267. [CrossRef]

26. Lee, S.; Kim, D.H.; Huh, C.; Pope, G.A. Development of a Comprehensive Rheological Property Database for EOR Polymers. In Proceedings of the SPE Annual Technical Conference and Exhibition, New Orleans, LA, USA, 4-7 October 2009. SPE-124798-MS.

27. Wassmuth, F.R.; Green, K.; Arnold, W.; Cameron, N. Polymer flood application to improve heavy oil recovery at East Bodo. J. Can. Pet. Technol. 2009, 48, 55-61. [CrossRef]

28. Singh, V.; Tiwari, A.; Tripathi, D.N.; Sanghi, R. Microwave enhanced synthesis of chitosan-graft-polyacrylamide. Polymer 2006, 47, 254-260. [CrossRef]

29. Singh, V.; Tiwari, A.; Tripathi, D.N.; Sanghi, R. Microwave promoted synthesis of chitosan-graft-poly(acrylonitrile). J. Appl. Polym. Sci. 2005, 95, 820-825. [CrossRef]

30. Rho, T.; Park, J.; Kim, C.; Yoon, H.K.; Suh, S. Degradation of polyacrylamide in dilute solution. Polym. Degrad. Stab. 1996, 51, 287-293. [CrossRef]

31. Galindo-Rosales, F.J.; Rubio-Hernández, F.J.; Sevilla, A.; Ewoldt, R.H. How Dr. Malcom M. Cross may have tackled the development of "An apparent viscosity function for shear thickening fluids". J. Non Newton. Fluid Mech. 2011, 166, 1421-1424. [CrossRef]

32. Barnes, H.A.; Hutton, J.F.; Walters, K. Rheology Series, vol. 3, An Introduction to Rheology; Elsevier Science Publishers B.V.: Amsterdam, The Netherlands, 1993; pp. 18-20.

33. Delshad, M.; Kim, D.H.; Magbagbeola, O.A.; Huh, C.; Pope, G.A.; Tarahhom, F. Mechanistic Interpretation and Utilization of Viscoelastic Behavior of Polymer Solutions for Improved Polymer-Flood Efficiency. In Proceedings of the SPE Improved Oil Recovery Symposium, Tulsa, OK, USA, 19-23 April 2008. SPE-113620-MS.

34. Wei, B.; Romero-Zerón, L.; Rodrigue, D. Oil displacement mechanisms of viscoelastic polymers in enhanced oil recovery (EOR): A review. J. Pet. Explor. Prod. Technol. 2014, 4, 113-121. [CrossRef]

35. Urbissinova, T.S.; Trivedi, J.; Kuru, E. Effect of elasticity during viscoelastic polymer flooding: A possible mechanism of increasing the sweep efficiency. J. Can. Pet. Technol. 2010, 49, 49-56. [CrossRef]

36. Xia, H.; Wang, D.; Wang, G.; Wu, J. Effect of polymer solution viscoelasticity on residual oil. Pet. Sci. Technol. 2008, 26, 398-412. [CrossRef]

37. Zirnsak, M.A.; Boger, D.V.; Tirtaatmadja, V. Steady shear and dynamic rheological properties of xanthan gum solutions in viscous solvents. J. Rheol. 1999, 43, 627-650. [CrossRef]

38. Rochefort, W.E.; Middleman, S. Rheology of Xanthan Gum: Salt, Temperature, and Strain Effects in Oscillatory and Steady Shear Experiments. J. Rheol. 1987, 31, 337-369. [CrossRef] 